\title{
ОПТИМИЗАЦИЯ УСЛОВИЙ РАЗЛОЖЕНИЯ СУРЬМАСОДЕРЖАЩИХ МЕТАЛЛУРГИЧЕСКИХ ОБРАЗЦОВ
}

Троеглазова А.В.

ФГБОУ ВО Сибирский государственный университет геосистем и технологий,

Новосибирск, Россия

a.v.troeglazova@sgugit.ru

DOI: 10.26902/ASFE-11_197

Одной из наиболее вредных примесей в металлургических образцах является сурьма, поэтому контроль ее содержания необходимо осуществлять на всех стадиях технологического процесса.

Цель настоящей работы заключается в установлении оптимальных условий разложения металлургических образцов для количественного переведения сурьмы из твердой фазы в раствор.

В качестве объектов для исследования применяли медный концентрат, металлургический шлак и пыль медного производства. Исследуемые образцы предварительно измельчали в шаровой мельнице PULVERISETTE 6 до частиц размером $(0,10 \pm 0,01)$ мм, высушивали в сушильном электрошкафу СНОЛ-3,5.3,5.3,5/3,5-И5М при температуре (105 \pm 5$)$ ${ }^{\circ} \mathrm{C}$ до постоянной массы. Разложение образцов осуществляли путем сплавления. Концентрацию сурьмы в растворах, полученных после разложения исследуемых образцов, определяли методом АЭС-ИСП на атомно-эмиссионном спектрометре с индуктивносвязанной плазмой SpectroArcos при длине волны 206,833 нм.

Для установления оптимальных параметров извлечения сурьмы из твердой фазы исследуемых образцов в раствор применяли метод четырехфакторного вероятностнодетерминированного планирования эксперимента при варьировании массы навески, температуры сплавления, времени контакта фаз и доли реагента в смеси.

Коэффициенты регрессии оценивали методом наименьших квадратов и методом Крамера, рассчитанные значения коэффициентов корреляции $\mathrm{R}$ и его значимость в виде коэффициента Стьюдента $t_{R}$ представлены в таблице 1.

Таблица 1 -Коэффициент корреляции Rи его значимость $t_{R}$ для частных функций

\begin{tabular}{|l|c|c|c|c|c|c|}
\hline \multirow{2}{*}{ Фактор } & \multicolumn{2}{c|}{$\mathrm{O}-1$} & \multicolumn{2}{c|}{$\mathrm{O}-2$} & \multicolumn{2}{c|}{ O-3 } \\
\cline { 2 - 7 } & $\mathrm{R}$ & $\mathrm{t}_{\mathrm{r}}$ & $\mathrm{R}$ & $\mathrm{t}_{\mathrm{r}}$ & $\mathrm{R}$ & $\mathrm{t}_{\mathrm{r}}$ \\
\hline $\mathrm{m}_{\text {нав}}, \Gamma$ & 0,9349 & 3,72 & 0,9473 & 4,18 & 0,9486 & 4,69 \\
\hline $\mathrm{t}^{\circ}{ }^{\circ} \mathrm{C}$ & 0,9752 & 6,24 & 0,9663 & 5,31 & 0,6501 & 1,47 \\
\hline ф, мин & 0,9746 & 6,15 & 0,9563 & 4,63 & 0,6877 & 1,60 \\
\hline доля реагента в смеси, \% & 0,9624 & 5,01 & 0,9535 & 4,48 & 0,9098 & 3,45 \\
\hline
\end{tabular}

По превышению значения $\mathrm{t}_{\mathrm{R}}$ критической величины $(2,030)$ для образцов O-1 и О-2 можно сделать вывод о значимости влияния всех четырех рассматриваемых факторов на степень извлечения сурьмы из твердой фазы в раствор путем спекания. При исследовании спекания образца О-3 установлено значимое влияние на степень извлечения аналита только двух факторов - массы навески и доли реагента в смеси (таблица 5).

На основании полученных результатов, представленных в таблице 3, были выбраны оптимальные условия спекания, позволяющие проводить количественное извлечение сурьмы (не ниже 96 \%): масса навески 0,1 г; температура сплавления $900^{\circ} \mathrm{C}$, длительность сплавления 60 мин, доля реагента в смеси $75 \%$.

Полученные результаты использовали для разработки методики выполнения измерений массовых долей сурьмы в металлургических образцах методом АЭС-ИСП в концентрационном диапазоне содержания аналита от 0,010 \% масс. до 5,0 \% масс. 